8-1-2017

\title{
Activity spotlight: Zika prevention
}

Breakthrough RESEARCH

Follow this and additional works at: https://knowledgecommons.popcouncil.org/departments_sbsr-pgy

Part of the Health Communication Commons, and the Public Health Commons How does access to this work benefit you? Let us know!

\section{Recommended Citation}

Breakthrough RESEARCH. 2017. "Activity spotlight: Zika prevention." Washington, DC: Population Council. 


\section{BREAKTHROUGH RESEARCH}

Breakthrough RESEARCH is the United States Agency for International Development (USAID)'s flagship project for social and behavior change (SBC) research and evaluation. We support countries to improve health and development by equipping governments, implementing partners, service delivery organizations, and donors with the data and evidence they need to integrate proven and cost-effective SBC approaches into their programs.

\section{FAST FACTS}

WHO? A consortium led by Population Council in partnership with Avenir Health, ideas42, Institute for Reproductive Health at Georgetown University,

Population Reference Bureau, and Tulane University

WHAT? A five-year cooperative agreement to drive the generation, packaging, and use of innovative SBC research

WHEN? August 2017 to July 2022

WHERE? Global

WHY? To expand the evidence base, increase healthy behaviors, and enable positive social norms through improved SBC programming

HOW? Breakthrough RESEARCH can work with a range of partners under a variety

of collaborative agreements

FOR MORE INFORMATION: Contact Laura Reichenbach Project Director at Lreichenbach@popcouncil.org or Hope Hempstone USAID AOR at hhempstone@usaid.gov

\section{Project Summary}

Breakthrough RESEARCH will catalyze social and behavior change (SBC) by conducting state-of-the-art research and evaluation and promoting evidence-based solutions to improve health and development programs around the world.

SBC approaches can enhance the impact and sustainability of health service delivery and other development programs by positively shifting healthseeking behaviors, improving provider behaviors, and fostering supportive social norms.

To advance the field of SBC, Breakthrough RESEARCH will work with a range of stakeholders as partners to identify information gaps, build consensus around priority learning agendas, and carry out innovative SBC research and evaluation. The project will address key questions such as "What works?" "How can it work best?" "Is it cost effective?" "How can it be replicated, scaled, and sustained locally?". To do this, Breakthrough RESEARCH will use cutting-edge approaches and methodologies that balance rigor and speed, and maximize cost efficiency in rapidly changing development and humanitarian environments. The consortium will also develop tailored tools, build capacity, and provide technical assistance to ensure that research findings and evidence-based recommendations are accessible, contextualized, and actionable.

\section{Activity Spotlight: Zika Prevention}

In collaboration with Breakthrough ACTION, our sister project led by the Johns Hopkins University Center for Communication Programs (JHU-CCP), Breakthrough RESEARCH is supporting and strengthening USAID's Zika response efforts to optimize SBC programming directed toward minimizing negative pregnancy outcomes in the agency's priority countries in Latin America and the Caribbean.

Breakthrough RESEARCH is leading an evidence review of commonly promoted Zika preventive behaviors and together with Breakthrough ACTION will develop a process for prioritizing these behaviors using criteria that considers efficacy, feasibility, and potential impact.

A key outcome of this process will be an evidence-based list of priority prevention behaviors that will be shared via the USAID Zika SBC Technical Working Group and through other relevant networks. Ultimately, the collaborative work will equip implementing partners with evidence-based guidance on how to strengthen Zika response efforts on the ground. 
Breakthrough RESEARCH will also conduct formative SBC behavioral research starting in four priority countries: Guatemala, El Salvador, Honduras and the Dominican Republic. This research will provide USAID and its community engagement partners with valuable insights about: knowledge, attitudes and behaviors in Zika prevention; exposure to and retention of key health promotion messages; and the relative effectiveness of different communication channels.

To promote knowledge sharing and innovation, Breakthrough RESEARCH will document lessons learned from SBC activities carried out under the USAID-led Zika response.

\section{What Will Breakthrough RESEARCH do?}

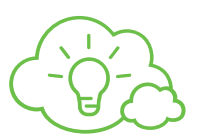

Build consensus around priority SBC research agendas. Breakthrough RESEARCH will develop consensus-driven research agendas that can reduce duplication, foster collective learning, and maximize resources. Learning agendas will be developed by engaging key stakeholders to identify research gaps and establish priorities around key SBC themes, such as provider behavior change and integrated programming.

- Expert consultations

- Priority global SBC research agendas
- Identification of key research gaps

- Guidance for investments, research, programs, \& policy

Generate rapid and high-quality evidence to enhance SBC programs. Breakthrough RESEARCH

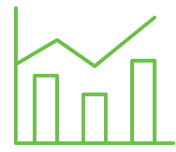
will use state-of-the-art research and evaluation methods to understand the impact of SBC programs and approaches, their cost, and the conditions needed for scale up, replication, and sustainability. Employing innovative research designs that apply insights from emerging fields such as behavioral economics and human-centered design, the project will generate data that can be used to inform real-time program adaptation as well as longer term planning.

- Impact evaluation

- Operations research

- Implementation science

- $\quad$ Cost \& impact modeling

- Cost \& economic evaluation
- Systematic reviews

- Formative research

- Secondary analysis

- Meta-analysis

Package and share what works for SBC programs. Breakthrough RESEARCH will translate existing and newly generated evidence into audience-tailored, action-oriented messages that are packaged in user-friendly language and accessible print and digital formats. These products will be shared widely through well-established knowledge management platforms.

- Briefs \& factsheets

- Data visualization \& infographics
- Videos \& multimedia presentations

- In-person \& virtual learning events

Put evidence into practice. Breakthrough RESEARCH will support USAID Missions, country-based SBC implementers, service delivery organizations, development partners, policymakers, donors, and other local stakeholders to integrate proven and cost-effective SBC approaches; interpret and contextualize evidence; and inform practical application in workplans, program designs, operational strategies, training guidelines, investment cases, or other implementation activities.

- Technical assistance

- Data use workshops
- Practical tools

- Monitoring \& evaluation frameworks

Visit our website to learn more. https://breakthroughactionandresearch.org/ 